\title{
COMPARATIVE ASSESSMENT OF WATER USE AND ENVIRONMENTAL IMPLICATIONS OF COAL SLURRY PIPELINES
}

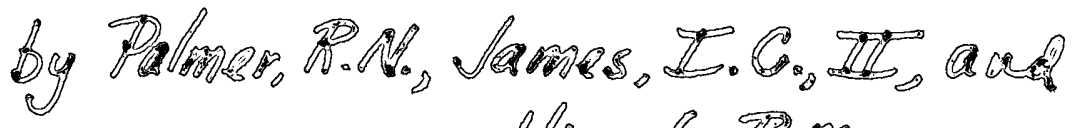

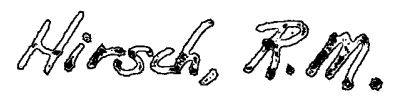

U.S. GEOLOGICAL SURVEY

Open-File Report 77-698

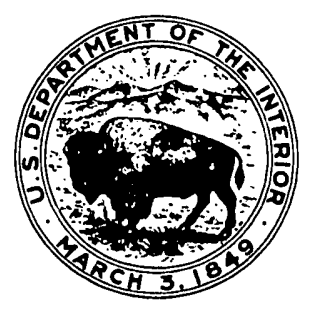




\section{COMPARATIVE ASSESSMENT OF WATER USE AND ENVIRONMENTAL IMPLICATIONS OF COAL SLURRY PIPELINES}

By Richard N. Palmer, Ivan C. James, II, and Robert M. Hirsch

U.S. GEOLOGICAL SURVEY

Open-File Report 77-698

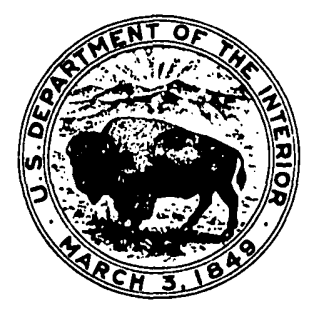




\section{U.S. DEPARTMENT OF THE INTERIOR CECIL D. ANDRUS, Secretary GEOLOGICAL SURVEY \\ V. E. McKelvey, Director}

For additional information write to:

Chief Hydrologist

U.S. GEOLOGICAL SURVEY, WRD

410 National Center

Reston, Virginia 22092 
'LABLE: OY' CONTENTS

Page

АВSIRRCT . . . . . . . . . . . . . . . . . . . . . . .

BACKCR()UND . . . . . . . . . . . . . . . . . . . . . . . . . . . . . . . . . . 2

COAL, SLURRY TRANSPORTS . . . . . . . . . . . . . . . . . . . . . . . . 3

Introduction . . . . . . . . . . . . . . . . . . . . 3

USGS Coal Slurry Model . . . . . . . . . . . . . . . . . . 4

Water Consumption . . . . . . . . . . . . . . . . . . 7

Energy Consumption . . . . . . . . . . . . . . . . 8

Water and Energy Comparison . . . . . . . . . . . . . . . . 9

Environmental Impacts . . . . . . . . . . . . . . . . . . 11

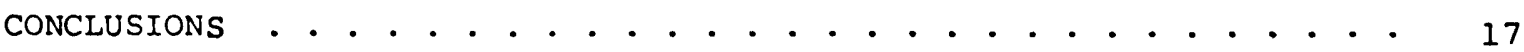

REFERENCES • . . . . . . . . . . . . . . . . . . . . . . . . 18

ILLUSTRATIONS

Figure 1.--Generalized cost for coal slurry pipeline system . • • • 20

2.--Cost of transport as a function of volume transported . . . 21

3.--Unit cost of transport as a function of volume transported . . . . . . . . . . . . . . . . 22

4.--Water requirements of slurry pipeline . . . . . . . . . . . 23

5.--Unit cost of slurry transport as a function of solids content............................

6.--Unit cost of energy and pipeline as a function of solids content . . . . . . . . . . . . . . . . . .

7.--Energy consumption as a function of water used in transport. . . . . . . . . . . . . . . . . 26

8.--Comparison of water consumed assuming 12.5 million tons per year ......................... 


\section{ILLUSTRATIONS--Continued}

Page

Figure 9.--Comparison of energy outrut of coal assuming

12.5 million tons per year. . . . . . . . . . . . .

TABLES

Table-1.--Optimal quantity of water demanded as a function of water cost for a 12.5 million ton per year coal slurry

pipeline . . . . . . . . . . . . . . . . . . 
COMPARATIVE ASSESSMENT OF WATER USE AND ENVIRONMENTAL

IMPLICATIONS OF COAL SLURRY PIPELINES

Richard N. Palmer, Ivan C. James, II, and Robert M. Hirsch

U.S. Geological Survey, National Center, Reston, Va. 22092

ABS'TRAC'

One of the most talked about issues with respect to the development, transportation, and conversion of the West's energy resources is the water requirement and its consequent impacts upon the ambience of the Western United states. In conjunction with other studies conducted by the U.S. Geological survey of water use in the conversion and transportation of the West's coal, an analysis of water use and environmental implications of coalslurry pipeline transport is presented.

Simulations of a hypothetical slurry pipeline of 1000-mile length transporting 12.5 million tons per year indicate that pipeline costs and energy requirements are quite sensitive to the coal-to-water ratio. For realistic water prices, the optimal ratio will not vary far from the 50/50 ratio by weight. In comparison to other methods of energy conversion and transport, coal-slurry pipelines utilize about $1 / 3$ the amount of water required for coal gasification, and about $1 / 5$ the amount required for on-site electrical generation.

An analysis of net energy output from operating alternative energy transportation systems for the assumed conditions indicates that both slurry pipeline and rail shipment require approximately 4-1/2 percent of the potential electrical energy output of the coal transported, and high-voltage, directcurrent transportation requires approximately 6-1/2 percent. The environmental impacts of the different transports options are so substantially different that a common basis for comparison does not exist. 
Background

Coal production in the United States is predicted to double in the next 10 years. Much of this new production will be of low-sulfur coal located in the western part of the country, in and along the Rocky Mountains. Although this low sulfur coal offers environmental advantages over other types of coal found throughout the country, it lies in areas far from most of the existing energy markets. Because the shipment cost of coal can represent two-thirds of its delivered price, the efficient transportation of this energy resource to its far away markets has assumed a new significance.

A variety of transport options are available for western coal, including shipment by rail, coal-slurry pipeline, coal gasification-pipeline transport and onsite electrical energy generation-high voltage transmission. Much has been written recently about the merits and drawbacks of each of these techniques, especially between rail and coal-slurry pipelines. It is not the purpose of this paper to add new fuel to that heated debate nor even to give a detailed comprehensive analysis of each of the transportation options. Rather, this paper will focus on three topics related to the transport of energy; water consumption, energy concumption, and environmental impacts. The paper begins with a description of a coal-slurry pipeline model that was created recently at the U.S. Geological survey. Insights gained from this model concerning potential tradeoffs between water consumption, the annual cost of the pipeline system, and energy requirements are presented. The water required for shipment of coal by slurry pipelines will then be compared with that required by other techniques of energy transport. A net energy analysis is made of slurry transport, rail shipment, and onsite electricity generation. Finally, generalized environmental impacts of each transport method are compared. It seems unnecessary to note that water availability may, in some instances, act as a constraint to the use of coal-slurry pipelines. It should be noted at the outset, however, that where water availability does limit the use of slurry pipelines, it will also impact heavily on the use of other energy transport technologies. 


\section{Introduction}

The idea of moving solids by means of a pipeline is not new. As early as the 1850's the technique was used in mining operations in California (Colorado School of Mines Research Foundation, 1963). It was not until the mid 1950's--with the construction of the 108-mile, 10-inch diameter Consolidated Coal Co. Pipeline in Ohio--that the technique was used on a large scale. Since that time only a handful of slurry-transport systems have been built in the U.S. and only one major coal slurry pipeline is currently in operation (Kiefner, 1976).

In the past few years, however, a number of major coal-slurry lines have been proposed. All of these pipelines would move coal out of the Rocky Mountain region eastward to large energy markets. Unfortunately, the availability of water near the areas where the coal is mined is often limited. It is the magnitude of these proposed projects and their potential for water consumption that induced the Geological Survey to investigate the natural resources implications of transport by slurry pipelines. T'wo of the initial items of interest--water consumption and energy requirements--were found to be not only important in the operation of coal slurries but intimately related.

A number of models have been developed to describe coal slurry pipelines, each with a different purpose (Lavingia, 1975; Chiang and Nichols, 1976; Faddick and DaBai, 1977). Regardless of the model's purpose or emphasis, several concepts are fundamental. From the perspective of a corporation building a slurry pipeline, the primary objective in using the pipeline is to reliably transport a required volume of coal at the lowest possible price. This goal is achieved by choosing an efficient design to which daily adjustments can be made. The designer has to consider not only the initial capital costs for such things as the pipeline, pumps, coal crushers and dewaterers, but the expected future cost of electricity and water as well. The design should be flexible enough to allow minor modifications in the system's operation whenever the costs of the inputs vary.

Aside from the cost of the system's components the designer must be familiar with the unique hydraulic characteristics of coal slurry transport. 
of great importance in the design is the velocity at which the slurry flows through the pipeline. The velocity must be great enough to keep the coal in suspension as it flows in the pipe and prevent it from settling along the pipe's bottom. If settling does occur, the pipeline can eventually become clogged and cause a shutdown of the system. On the other hand, there are real incentives for keeping the velocity in the pipe small. High velocities result in increased frictional headloss, pump damage, and corrosion, and erosion of the pipeline. Therefore the design velocity that is chosen must strike a compromise between all of these factors.

Figure $l$ is a generalized illustration of how, for a given tonnage of coal, the costs for shipment vary with pipe size (Faddick and Gusek, 1977). The figure is composed of three curves; energy related costs, pipeline cost, and total costs. The total cost curve shows the typical convex shape which results from an increasing cost for the pipeline and decreasing cost for energy as the pipe diameter increases. The lowest point on the total cost curve is the design which results in the minimum total annual cost and is optimal from an annual cost standpoint.

\section{USGS Coal Slurry Model}

The model used in this analysis captures all the above interrelated factors. The head loss and energy requirements associated with the pumping of the slurry consider basic hydraulic principles as well as recent pipeline experience (Faddick, 1976; Aude, 1977; Monfort, 1972). In the simulations that were run, several different pumping velocities were chosen. Calculations were made of the critical settling velocities of the slurries and those runs on which the design velocity was lower than the critical velocity were eliminated as infeasible. Energy requirements for the coal grinding and dewatering were taken from recent publications (Wilson and Miller, 1974; Aude, 1977; Shen, 1977; Halvorsen, 1976).

Although research has begun on the effect of coal particle size, this parameter was not varied in this analysis (Faddick and DaBai, 1977). In this study it was assumed that the coal would be crushed to the same particle size distribution as that used by the Black Mesa system in Arizona--the only major 
coal slurry system currently operating in the United States. In addition, it was initially assumed that the coal-to-water ratio in the slurry would be 50/50 by weight. This second assumption was later relaxed and the ratio varied.

Figure 2 is a plot of the optimal pipe diameter for a wide range of delivery rates. The pipeline length in this and all other examples is 1,000 miles with a drop in elevation of 5,200 feet. Other assumptions for the figure include a price of water of $\$ 0.30$ per thousand gallons, a price of electricity of $\$ .0182$ per kilowatt-hour and an interest rate of 8 percent on borrowed money. Equations for the cost of the pipeline, cost of the pumps, slurry preparation, and dewatering facilities were taken from a recent report sponsored by the National Science Foundation and are given in 1975 dollars (Chuang and Nichols, 1976). The cost of chemicals used in the dewatering process are not included in these cost estimates. Economies of scale can be seen in this figure both for annual energy related costs and total annual costs as a result of the rapid decrease in frictional head loss as pipe size increases.

The economies of scale can best be seen, however, in a unit cost format, as shown in figure 3. The advantages of large pipelines over small systems are obvious. From the available data it appears that the unit costs decrease rapidly with increasing size for smaller pipelines and continue to decrease for lines carrying 30 million tons per year. The rate of unit cost decrease is greatest for shipments in the 4- to 10-million-ton range. In this range unit cost decreases over 50 percent. Beyond the 10-million-tons-peryear value unit costs continue to decrease but at a much slower rate.

It is very important to note, however, that although this unit cost decrease exists, there is no corresponding decrease in the water required per ton. For a shipment of a given quantity of coal, the only factor which affects water use is the coal-to-water ratio of the slurry. Once that ratio has been established the quantity of water required is a simple linear function of the amount of coal shipped.

Figure 4 illustrates this point. In this figure the number of acre-feet of water required to transport a given quantity of coal is given as a function 
of coal transported. The slurry content in this figure varies from a $40 / 60$ coal-to-water ratio to a $60 / 40$ ratio. This range of ratios was chosen because it appears that all potentially feasible and interesting ratios lie in this range. If the quantity of coal transported is 25 million tons per year, the difference between a 60/40 coal-to water ratio and a 40/60 ratio is approximately 15,000 acre-feet of water per year. A shift from the often quoted.50/50 ratio of coal-to-water to a 60/40 ratio results in a decrease in water use of 6,000 acre-feet per year or equivalently, a decrease in water use of approximately 30 percent.

Since changing the coal-to-water ratio is the only way to change the total quantity of water used per ton of coal shipped, a number of model runs were made with different coal-to-water mixtures. The results of one such computer run are shown in figure 5. This figure shows the change in cost per ton transported as a function of the solids-to-water ratio. The size of the transport system in this case was chosen to be 12.5 million tons per year and 1,000 miles in length. This size was chosen for two reasons. First, it was felt that this volume of coal transport is in the vicinity of the minimum volume that would be required to make coal slurries competitive with already existing railroad lines. Second, this rate of coal delivery corresponded to the rate used in other studies done by the USGS and thus provides a basis for comparison of several forms of coal conversion and transport.

The shape of the curve in this figure is somewhat surprising. As the coal content in the slurry is increased from 40 percent, the cost of shipment decreases. This decrease continues until the solids content passes 50 percent and then rapidly increases. Two important factors combine to give this curve its shape--the pipeline cost and energy related costs. These two individual costs are extracted from the total cost and presented in figure 6 . Pipeline costs are shown to decrease as solids concentration increases and this can be explained in the following fashion. As the solids concentration in the slurry increases, the volume of slurry needed to deliver a prescribed weight of coal decreases. Since the volume of slurry decreases, the diameter of the pipe can be decreased and thus the cost of the pipe decreases. 
On the other hand, as the solids concentration increases in the slurry the slurry viscosity-- that is, its resistance to flow)--increases. This increase in viscosity causes an increase in the frictional headloss in the pipeline, thus larger pumps are required and more energy is needed to transport the slurry. As the solids concentration in the slurry increases, the energy related cost rises at an increasing rate as shown in figure 6 .

With this knowledge the shape of the total cost curve in figure 5 can be explained. In the range between 40 to 50 percent solids content, pipe cost decreases more rapidly than energy related costs increase and the result is a decreasing total cost. Above the 50 percent solids concentration, energy related costs increase more rapidly than pipe cost decreases and total costs increase. It is appropriate to note that the minimum total cost on the curve is at a ratio containing 52 percent coal, quite near the 50 percent coal ratio for which most large coal slurry pipelines have been designed.

\section{Water Consumption}

Figure 5 indicates that at an optimal design the quantity of water required to move 12.5 million tons of coal is near 8,500 acre-feet. This quantity of water corresponds to a slurry containing 52 percent coal. If the concentration of coal in the slurry is increased to 60 percent, the corresponding requirement for water is only 6,100 acre-feet--resulting in a decrease in demand of 2,400 acre-feet per year. However, shifting this ratio of coal-to-water increases the annual cost of the system from $\$ 4.72$ per ton to $\$ 4.94$ per ton or about $\$ 2.75$ million per year. This $\$ 2.75$ million represents the approximate cost of conserving 3,000 acre-feet of water; or on the average, the cost of the water conserved is over $\$ 1,000$ per acre-foot. From the information contained in Figure 5 an implicit value of water can be determined for various pipeline designs. These implicit values represent the marginal productivity of watex in a pipeline that delivers 12.5 million-tons-per-year. They are the maximum cost to which water can rise before there is an economic incentive to consume less water by altering the pipeline's design. Using the implicit values of water, the sensitivity of the pipeline's design to water cost and the annual consumption of water can be determined. The quantity of water consumed as a function of water price is 
presented in table 1. Were water a free good, the pipeline would be designed to consume 8,500 acre-feet per year. As the cost of water increases, the design of the pipeline would change so that less water is consumed. The rate of this decrease in the total quantity of water consumed is fairly constant, but quite small. The price of water must increase from 0 to $\$ 1,000$ per acre-foot before there would be a 10 percent decrease in the water consumed.

Before it is suggested that pipelines be designed to use less water, it is useful to compare the costs of such a shift in design to the marginal value of water in the west. Although no number can serve to show the value of water for all uses, the maximum marginal value for water used in agriculture in the Colorado River basin is estimated at $\$ 25$ per acre-foot (Anderson and Keith, 1977). The figures in table 1 indicate that if the pipeline were charged this price for water it would have little impact on quantity of water consumed. This cost could be doubled or quadrupled and the optimal design for the pipeline would require only 1 or 2 percent less water per year. Thus the optimal design for the pipeline is very insensitive to changes in the cost of water. It is only if the cost of water increases dramatically--to values 40 and 50 times the current marginal value of water--that the optimal design will result in a pipeline that consumes substantially less water.

\section{Energy Consumption}

As mentioned previously, not only does a decrease in the amount of water used increase the cost of shipment but it increases the amount of energy that is consumed in that transport. Figure 7 is a plot of the electrical energy required for the pumping of the slurry as a function of the coal-to-water ratio. At a $50 / 50$ ratio 660 million kilowatt-hours of electricity are needed to transport the slurry. Were the ratio adjusted to contain 60 percent coal, the energy requirement would increase to 829 million kilowatts, an increase in energy consumption of 25 percent. If the cost of electricity is assumed to be near 1.8 cents per kilowatt-hour, the increase in electrical cost per year would be over $\$ 3$ million. It is impossible to vary the solids ratio in the slurry without having a significant effect on the energy consumption. Throughout the range surrounding the 50/50 solids ratio, a decrease in water consumption results in an increase in the energy required. Furthermore, as 
the solids content of the slurry increases, greater and greater amounts of energy are required for each percentagc decrease in the coal-to-water ratio.

Thus, the following preliminary conclusions can be made. The movement of coal by slurry pipeline is a somewhat water-intensive technique. To move 12.5 million tons of coal requires approximately 8,500 acre-feet of water annually--a quantity sufficient to serve the municipal needs of a city of 75,000. The precise quantity demanded for the slurry is not fixed, however, but rather a variable. To decrease water requirements significantly results in an increase in annual operating costs and a substantial increase in the electrical demands of the slurry system.

Water and Energy Comparison

To determine exactly how water-intensive coal slurry pipelines are as a means of transporting energy, a comparison was made with several other available alternatives. These alternatives included onsite power generataion with the energy transported with high voltage lines, coal gasification with the gas transported by pipeline, and coal transport by unit trains. The setting for this comparison is the Yampa River basin in northwest Colorado. For the analysis it was assumed that 12.5 million tons of coal would be mined each year in the Yampa River Basin and its energy transported 1,000 miles to Houston, Tex. by one of the four methods just described. Figure 8 presents the total quantity of water which would be lost to the Yampa River basin by each of the four methods. In the cases of coal slurry pipelines and rail shipment, more water would eventually be consumed when the coal was converted to a more usable form of energy in Houston. However, this conversion would take place outside of the Yampa basin and would not involve the use of water from the dry Rocky Mountain region but rather from an area which typically has ample water. It was assumed that both the gasification plant and mine-mouth powerplant would use wet mechanical draft cooling towers and would meet all air and water quality standards. Energy generated at the mine-mouth plant was assumed to be transported 1,000 miles by means of 600 kilovolt direct current powerlines. The coal-to-water ratio in the slurry was assumed in this case to be 50/50. From the figure it can be seen that onsite generation would require about 4.8 times as much water as coal slurry pipelines, and coal gasification 
would require about three times as much water as slurry pipelines. The water requirement for the transport of coal by rail was considered negligible compared to these other quantities. From this comparison it is clear that two of the three energy transport options require much more water than coal slurry pipelines. Rail transport is the only shipment means that does not use large quantities of water.

In addition to water use, the energy efficiency of the various transport options is of importance. There are certainly advantages to using the transport alternative which yields the greatest amount of energy to be consumed. To determine this value, a type of "energy analysis" was made of the four options. In contrast to recent "net energy analysis" (Gilliland, 1977), however, no attempt was made to trace all inputs of energy into the system. Rather, the boundary around the system of interest was drawn quite tightly and only those energy requirements and losses that occurred on a yearly operating basis were used. For example, the energy that was consumed in producing the machines that manufactured the molds that produced the steel which made the pipeline were not considered. To illustrate briefly, the primary energy requirements of the coal slurry system were considered energy needed to grind the coal, pump and dewater the slurry, and the energy needed to vaporize the water from the coal which could not be removed by dewatering. Similarly the only energy requirement considered for rail transport was that of the energy needed to drive the locomotives. No attempt was made to estimate the energy required to build the locomotives. The boundaries were drawn around the other two systems in a similar fashion.

Figure 9 shows the results of the energy analysis which assumed a 12.5 million ton per year input of coal. The bars indicate the amount of electrical energy delivered to Houston, Tex. at the completion of each process. For coal slurry pipelines, for instance, this value is the energy produced by 12.5 million tons of coal after the coal has been shipped by pipeline and converted to electricity in Houston. The same concepts applied to the shipment at 12.5 million tons of coal by unit trains. The example for coal gasification is somewhat different. In this case the bubble shows the number of cubic feet of synthetic gas that could be produced. This value was not converted to an energy output in kilowatt-hours because it was felt 
unlikely that such a conversion would take place. It seems more probable that the energy content of this fuel would be used in ways other than in the combustion of large powerplants.

For the three methods that were compared, the results are remarkably similar. At the end of the process each of these techniques resulted in approximately 30 trillion kilowatt-hours per year. None of these three methods showed any significant advantage over the other. Power transmission by high voltage lines consumes 6.5 percent of the potential electrical output of a power plant fed by 12.5 million tons of coal per year, coal slurry transport consumes 4.6 percent and unit trains consumes 4.2 percent. These values indicate that the energy used to transport the coal and electricity is only a small fraction of the energy produced. Two facts should be noted. First, the coal that was used in this example was of high BTU content, specifically 11,460 BTUs/pound. Because the tonnage would remain constant, tho use of a coal with a lower BTU value would affect the results of this analysis. Since water consumption in a pipeline is proportional to the tonnage of coal shipped, a lower BTU value of coal would result in a lower energy efficiency. Water consumption in the case of the mine-mouth alternative is proportional to the heat content of the coal, thus lowering the BTU value of the coal would affect its water use but would not affect the energy efficiency in this analysis. Water consumption is proportional to tonnage in the case of slurries while it is proportional to heat content in the case of mine-mouth power generation. Secondly, the amount of coal transported also affects the result of the analysis. Increasing the volume of coal shipped would proportionately increase the efficiency of coal slurry pipelines and decrease the efficiency of onsite generation. As mentioned previously, the shipment of 12.5 million tons of coal per year is near the minimum transport level for which coal slurry pipelines are competitive. The comparative energy efficiency of coal slurries would improve if the volume of coal shipped were to increase substantially.

Environmental Impacts

Regardless of the transport technique chosen, the shipment of millions of tons of coal out of the West will have important environmental impacts aside 
from those strictly associated with water and energy use. A number of interesting papers have been written describing these impacts, both by members of academia and by representatives of the competing transport industries (Gray and Mason, 1975; Wasp, 1975; Faddick and Gasek, 1977; Menk, 1975). The remaining portion of this paper will briefly summarize some of these impacts, with emphasis placed on those which are expected to result from the use of coal slurry pipelines. These impacts will then be briefly compared to those which would occur using other transport techniques. Such a comparison does little to indicate which means of transport is best. Rather the comparison serves to illustrate the advantages or disadvantages one technique might have over another in a given set of circumstances. Such information is, of course, helpful in making an intelligent evaluation of particular energy transportation options in a given situation.

Evaluating the environmental impacts of any activity can be a cumbersome task. Like a net energy analysis, there are rarely any clear lines drawn around the system of interest and the point at which impacts begin and end often appears blurred. To simplify this process, those impacts associated with the use of coal slurry pipelines will be classified into one of the three following categories--impacts associated with route selection, impacts which occur during pipeline construction, and impacts which occur during the operation of the pipeline. These categories will be discussed separately but their impacts will be seen to often overlap.

Although no direct impacts occur during the planning of the pipeline route, it is in this stage in which numerous environmental impacts can be avoided and others minimized. Successful planning results from a compromise between several objectives. The primary objective for the builders of the pipeline is to minimize the pipeline's cost. This is accomplished by minimizing the pipeline's length, that is, by making its route from the source of coal to its point of destination as straight as possible. The directness of the route is primarily constrained by the topography of the land over which the pipeline travels. By neccessity, routes which contain grades greater than 16 percent, which traverse extremely rough terrain, or which cross major rivers are to be avoided. But aside from those physical constraints, the planning of the pipeline's route should involve other environmental factors. 
Because of the noise produced by the pipeline pump stations and the disturbances that are created during the pipeline's construction and occasional repair, attempts should be made to avoid certain types of areas. These areas include populated regions, historic landmarks, areas of archaelogical significance, and those whose ecology could be easily upset. A careful multiobjective analysis of various potential routes in the planning stage can result in explicit statements of the tradeoffs between the cost of the pipeline and its potential impact on environmental considerations along the pipeline's route. These tradeoffs can then be used to determine a route which is a best compromise solution between the various objectives of interest. An analysis of this type done early in the planning stage will bring to light all of the important economic and ecological factors which should be considered in determining the pipeline's route.

Once a route has been selected, construction of the pipeline can begin. slurry pipeline construction is similar to other types of pipeline construction and its environmental impacts will be of the same magnitude. The major impact during construction is the disturbance to the soil and surrounding areas due to land clearing and earth moving activities. These activities include the excavation of the pipeline trench, construction of temporary roads and the movement of heavy industrial machinery. Careful erosion control precautions, especially in areas of highly erodable soils or on lands of high slope, must be taken to prevent the discharge of excessive amounts of sediment to streams or rivers as construction progresses. Pipeline construction has the advantage of moving quickly and construction activities at a given spot usually last no longer than 2 to 6 weeks. After this period of time prompt revegetation of the area can minimize the impact to streams and the land caused by erosion. Since the pipeline is almost always buried beneath the ground's surface, the laying of the pipeline through rivers and streams may cause major, momentary impacts. The minimization of these impacts can only be handled on a case-by-case basis. Once the pipeline has been put into place the streams crossed can return to normal and the land can be returned to its previous use. 
Numerous types of environmental impacts can occur during the operation of a slurry pipeline: One major concern with the use of slurry pipelines that has been voiced is the potential for water pollution. Water is used in two distinct processes in coal slurry transport. A small quantity of water is used to clean the coal before it is shipped. After the cleaning process this water is sent to a settling tank where the large particles are removed from the water by gravitation. The water is then recycled through the cleaning process and no water residuals are discharged to the environment. The second purpose for which water is used is as a transport medium. At the end of the pipeline this water is separated from the coal in flocculating tanks using long chain polymers. Although expensive, this process lowers the coal concentration in the water to approximately 30 parts per million and then the water is used for cooling purposes. Once again, none of this water is discharged directly into the environment.

At the locations where the coal is prepared for shipment and dewatered, noise and fugitive dust can be a problem. These potential problems seem to be handled adequately with current technology at the Black Mesa facility without major difficulties. Pump stations along the pipeline can also be a source of noise pollution, but if located away from population centers they present no significant problems.

The most severe environmental impact which could occur involving coal slurry transport is the rupture of a pipeline or the failure of a pumping station. If either of these occurred there is the possibility that quantities of coal slurry might be spilled. However, precautions have been taken to prevent extreme loss if either of these situations do occur. Were a pipeline to rupture, the flow of slurry would be automatically stopped until the rupture had been repaired. This would require the sealing of the pipeline above and below the rupture and possibly the draining of the pipeline near the rupture. Storage reservoirs would be located at each of the pumping stations for this purpose. The only slurry lost would be that which escaped before the system was stopped. In addition, excess pumping capacity is available at all of the pump stations. If one pump station were to fail, the slurry would be by-passed around that station using the excessive pumping capacity of the preceding station and pumped onto the next operable station. In this case 
little, if any, slurry would be lost. Thus far, there is no record of any slurry system suffering a rupture or pump failure that resulted in a large slurry spill. Under normal situations the pipeline itself has little impact, running two and a half to three feet underground, quietly and out of sight.

Many of the impacts which result from use of alternative transport options are quite similar to that of coal slurry pipelines. In the case of coal gasification, a pipeline similar to that used for a slurry would be built and would have the same impacts during its constructions. One disadvantage of the gas pipeline in its operation would be that, were a leak or rupture to occur, the potential for an explosion would exist. This is not the case with coal slurry pipelines, since they can neither burn nor explode. Although the potential for gas line explosions do exist, there are numerous pipelines already in existence and the relative safety has been proven.

Were onsite generation and power transmission used as an option, two major impacts would occur. First, rather than having a buried pipeline, an exposed power transmission line would run the length of the project. Unlike the pipeline, the land below the power transmission lines would have to be maintained and could not revert back to its previous use. Second, producing the coal onsite and transmitting the energy brings up an interesting question of equity. If the energy is generated onsite not only are large quantities of water consumed but the pollution associated with a large coal power plant is produced--not at the point of consumption but at a location hundreds of miles away. Due to the nondegradation portions of the Clean Air Act, this question is of interest. Is it better to foul an air that is currently pristine but where few people would be affected or to further pollute an air which millions of people breathe?

The impacts of railroads, currently the major movers of coal, are well known. The two most cited impacts are those of noise vibrations and traffic congestion. A fully loaded unit train comprised of over 100 cars, each carrying 100 tons of coal, can create noise levels of 88-98 decibels at a 50-foot distance. This noise level, together with the vibrations caused by the train, can have a very negative impact on the town through which 
the train passes. Those negative impacts are compounded by the disruption to traffic a slow moving, one hundred car train can create. For comparison, 12.5 million tons of coal per year can be transported by one pipeline or 1,250 unit trains per year. 
It is extremely difficult to make a comprehensive, comparative assessment of the environmental, energy use, and water consumption impacts of the four transportation alternatives that have been discussed. Aside from their energy and water use, an adequate framework for comparison does not exist. However, the following comments can be made.

Although each transport option has negative impacts, the impacts are not severe enough to prevent their use in most situations. If an environmental assessment is made at the mine site, unit trains and slurry pipelines have major advantages. Neither of these techniques produce at the minesite the major air pollution impacts that are associated with coal gasification or onsite electricity generation. They are, however, only techniques of transporting coal and the air pollution impacts will be encountered wherever the coal is converted into energy. Unit trains do present the disadvantage of creating disturbances and disrupting traffic in the towns through which they pass. If operated properly coal slurry pipelines produce less significant impacts. A pipeline does present the potential danger of creating a major negative impact if it were to rupture.

On the basis of their energy efficiency, none of the four methods appears to be clearly superior. The relative rankings of the four depend upon the quantity of coal delivered and the distance over which it is transported. In the analysis presented the energy efficiencies were almost identical. Increasing the quantity of coal transported would increase the relative efficiency of coal slurry pipelines and place it at a slight advantage over the other options. Decreased heat value of the coal would place both unit trains and slurrys at some disadvantage to the other methods.

It is in the water consumption of the four techniques that the clearest distinction can be drawn. Here, unit trains hold a clear advantage using only a negligible amount of water. Coal slurries, using about 9,200 acre-ft of water a year, are followed by coal gasification and onsite generation, using 28,000 and 44,400 acre ft per year respectively. 


\section{REFERENCES}

Anderson, J. C., and Keith, J. E., 1977, Energy and the Colorado River: Natural Resources Journal, v. 17, no. 2, p. 157-168.

Aude, T. C., et. al., 1971, slurry piping systems trends, design methods, guidelines: Chemical Engineering, v. 78, no. 14, p. 74-90.

Aude, T. C., 1977, Research and development for slurry pipeline system design: 2nd International Technical Conference on Slurry Transport, Las Vegas, Nevada, 1977, Proc., p. 56-63.

Chuang, K. C., and Nichols, D. G., 1976, The pipeline transmission of Coal and Coal Derived Fuel Gases: West Virginia University, Morgantown, West Virginia, M.S. Thesis, $210 \mathrm{p}$.

Colorado School of Mines Research Foundation, 1963, The Transportation of Solids in Steel Pipelines: Colorado School of Mines, Golden, Colorado, 125, p.

Faddick, R. R。, and DaBai, G. S., 1977, Optimization of particle size distribution for coal slurry pipelines: 2nd International Technical Conference on Slurry Transport, Las Vegas, Nevada, 1977, Proc., p. 112-123.

Faddick, R. R., and Gusek, J. J., 1977, The environmental and pollution aspects of coal slurry pipelines: 2nd International Technical Conference on Slurry Transport, Las Vegas, Nevada, 1977, Proc., p. 73-82.

Gray, W. S., and Mason, P. F., 1975, What the coal man should know in the planning stage: Coal Age, v. 80, no. 9, p. 58-62.

Gilliland, M. W., ed., Energy analysis a new public policy tool: Washington, D.C., Am. Assoc. for the Adv. of Sci., (in press). 
Halvorsen, W. J。, 1976, Slurry preparation, separation and utilization: International Technical Conference on Slurry Transport, Columbus, Ohio, 1976, proc., p. 4-1-4-13.

Kiefner, J. F., 1976, Review of slurry system projects in the U.S.:

International Technical Conference on Slurry Transportation, Columbus, Ohio, 1976, Proc., p. 10-1-10-24

Lavingia, N. J., 1975, The economics of pipeline transportation of mineral commodities: Colorado School of Mines, Golden, Colorado, Ph. D. Thesis, 93 p.

Menk, L. W., 1975, Hearings before the Committee on Interior and Insular Affairs, House of Representatives, 1st Session on H.R. 1863, 2220, 2552 and 2986: 94th Congress, Serial No. 94-8, p. 917-959.

Montfort, J. G., 1972, Black Mesa coal slurry line is economic and technical success: Pipe Line Industry, May, 1972, p. 42-45.

Shen, S. C., 1977, Dewatering equipment for coal slurry pipeline: 2nd International Technical Conference on Slurry Transport, Las Vegas, Nevada, 1977, Proc., p. 50-55.

Wasp, E. J., 1975, Progress with coal slurry pipelines (comparison with unit trains): American Mining Congress Convention, San Francisco, 1975。

Wilson, E. B., and Miller, F. G., 1974, Coal dewatering--some technical and economic considerations: Mining Congress Journal, v. 60, no. 9, p. 116-121. 


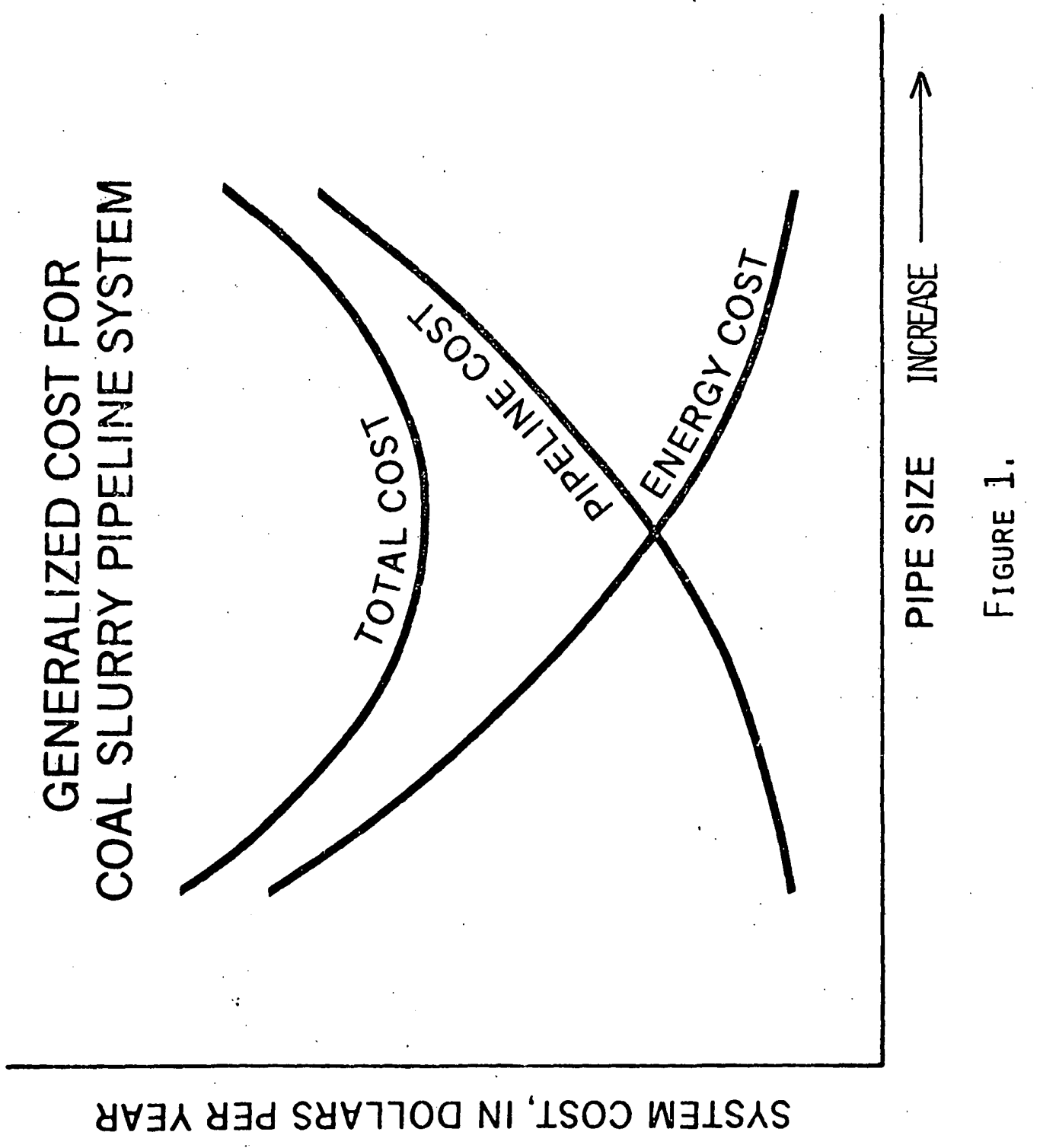




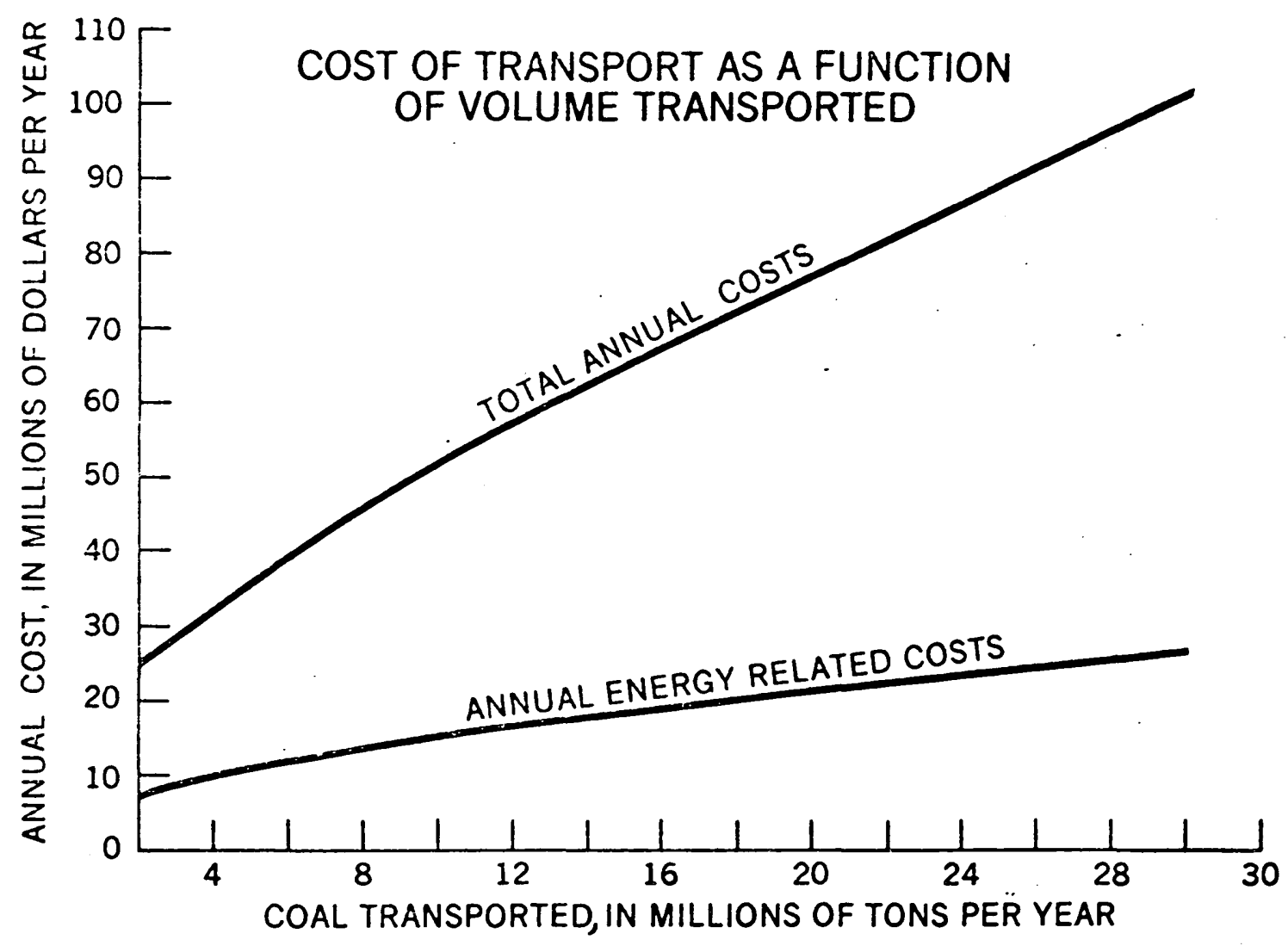

Figure 2. 


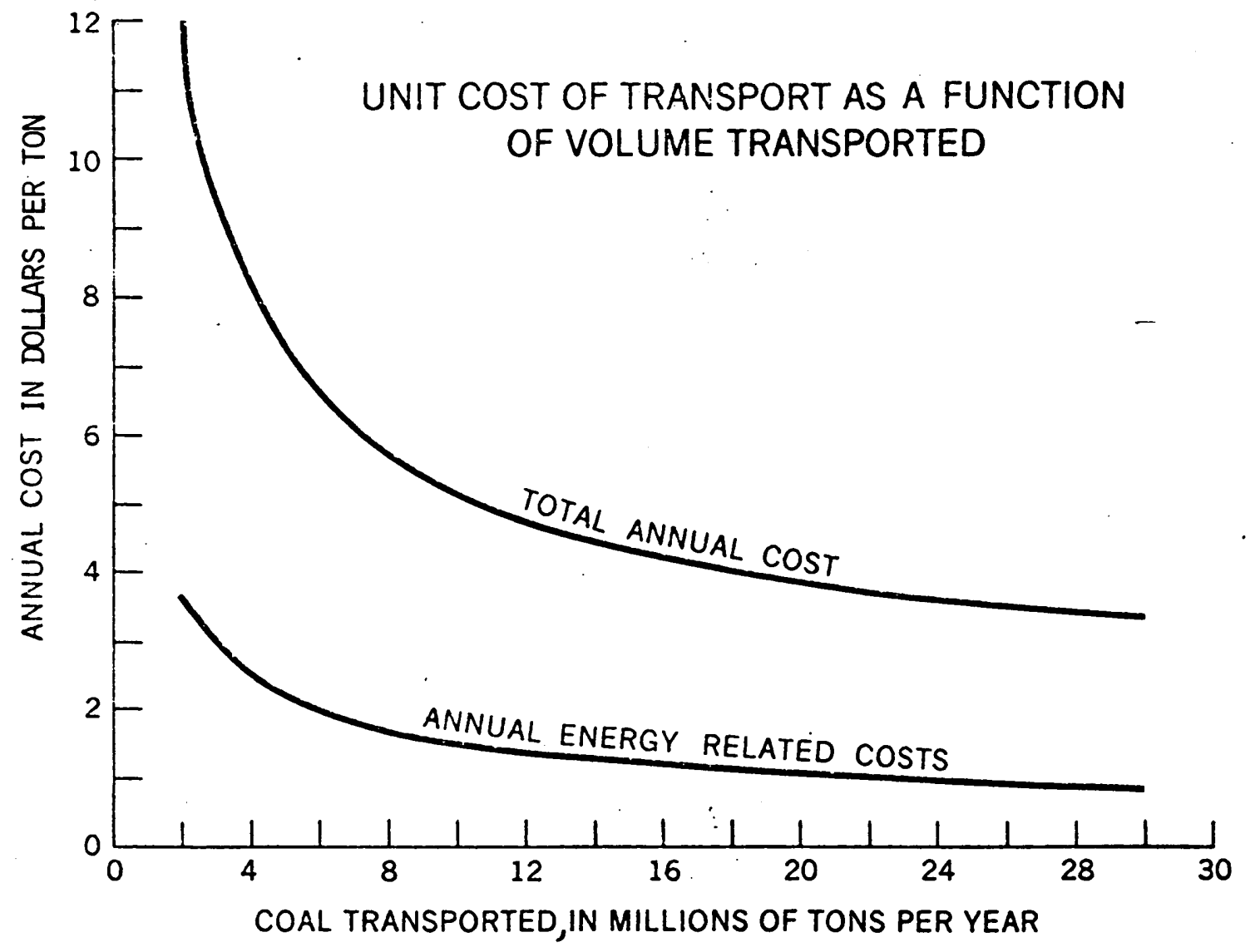

Figure 3. 


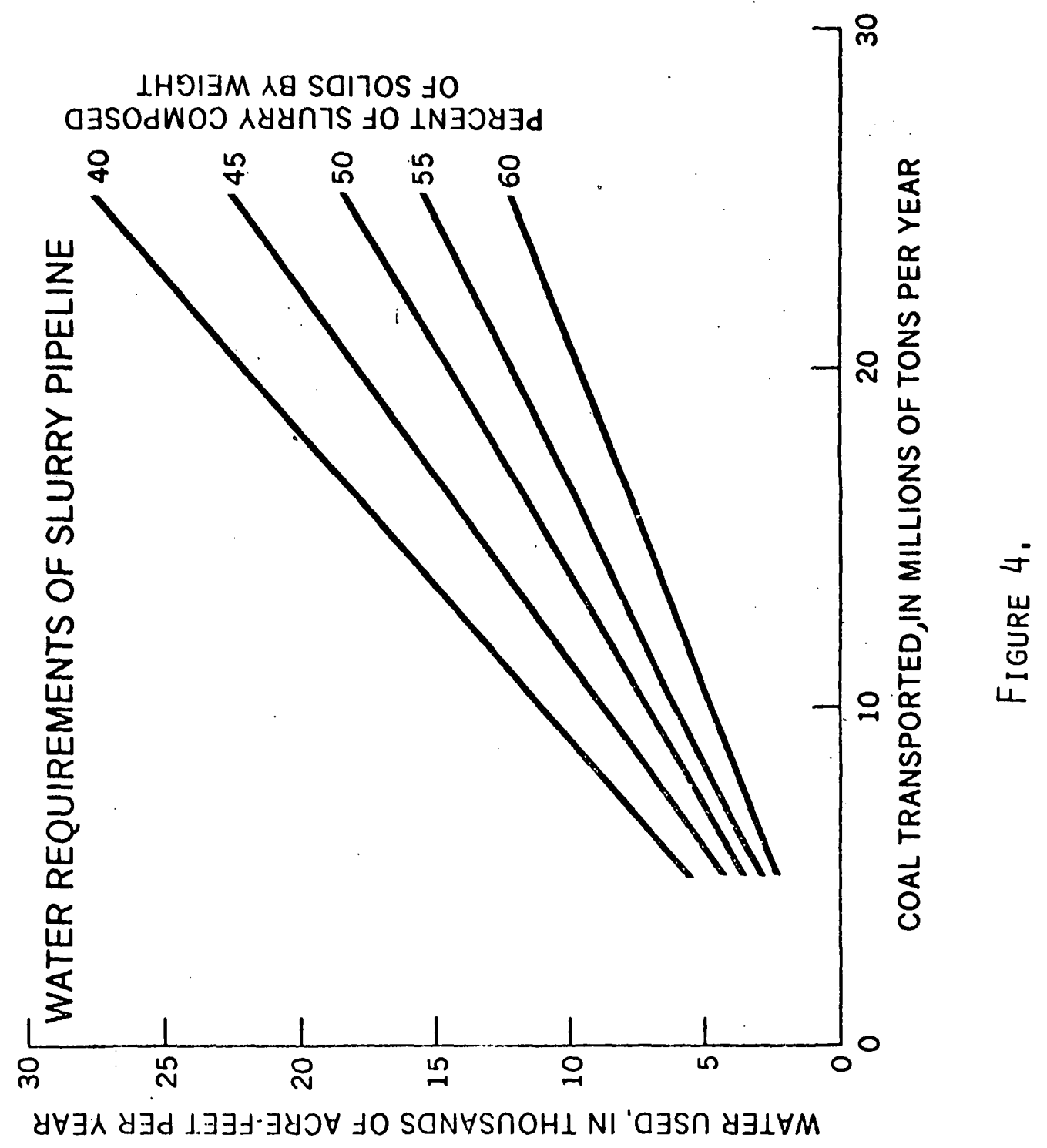



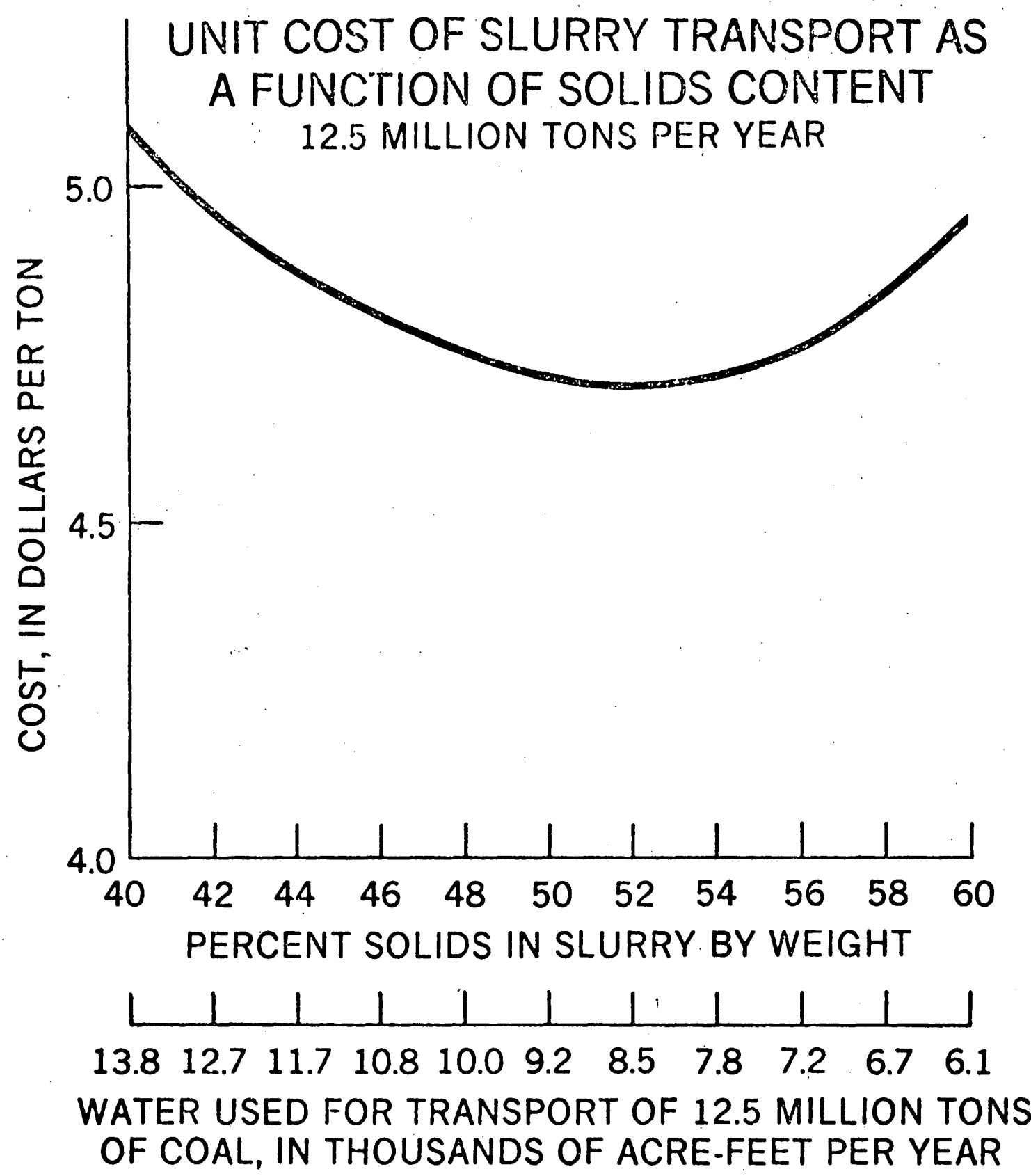

FIGURE 5 . 


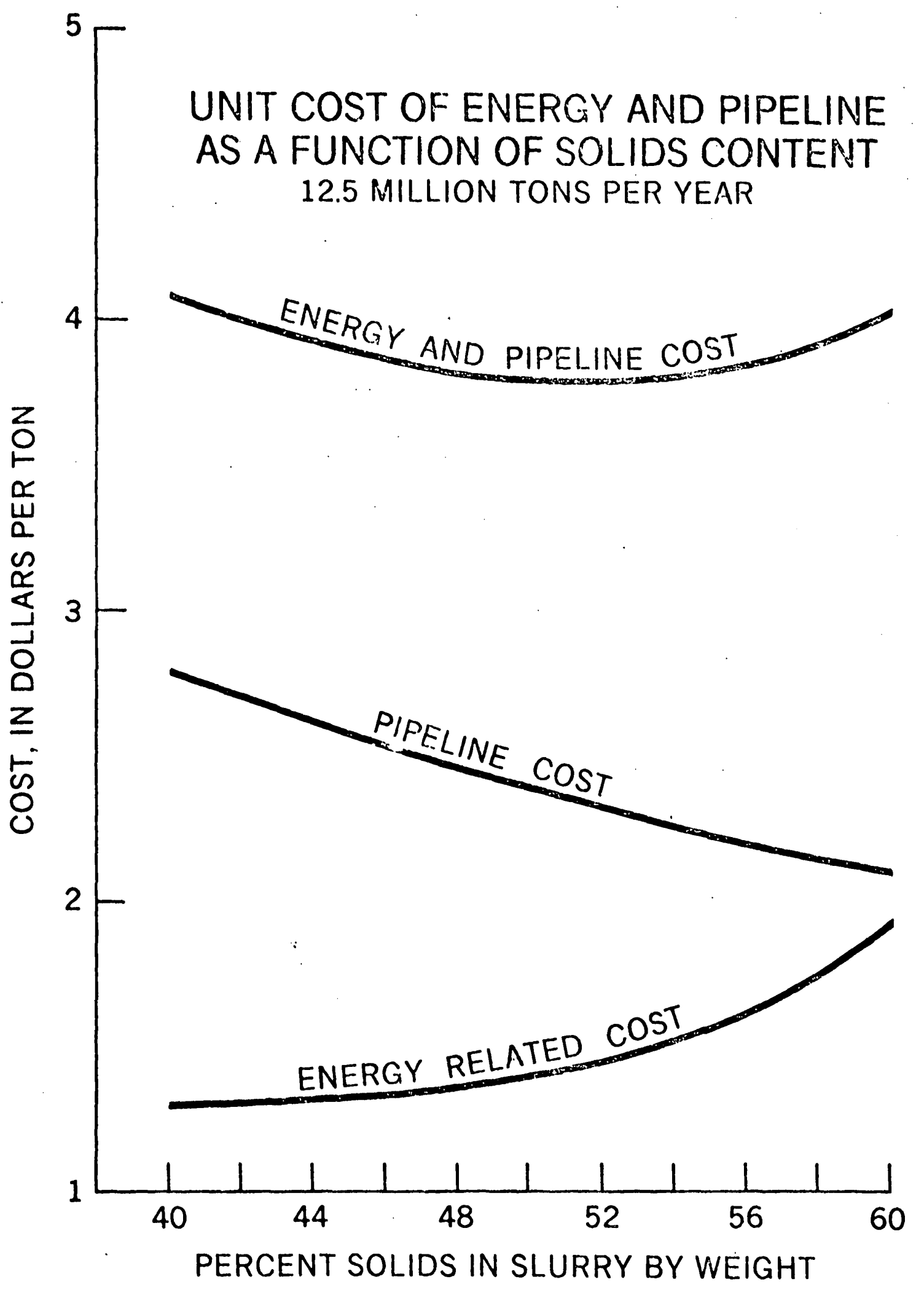

FiguRE 6 . 


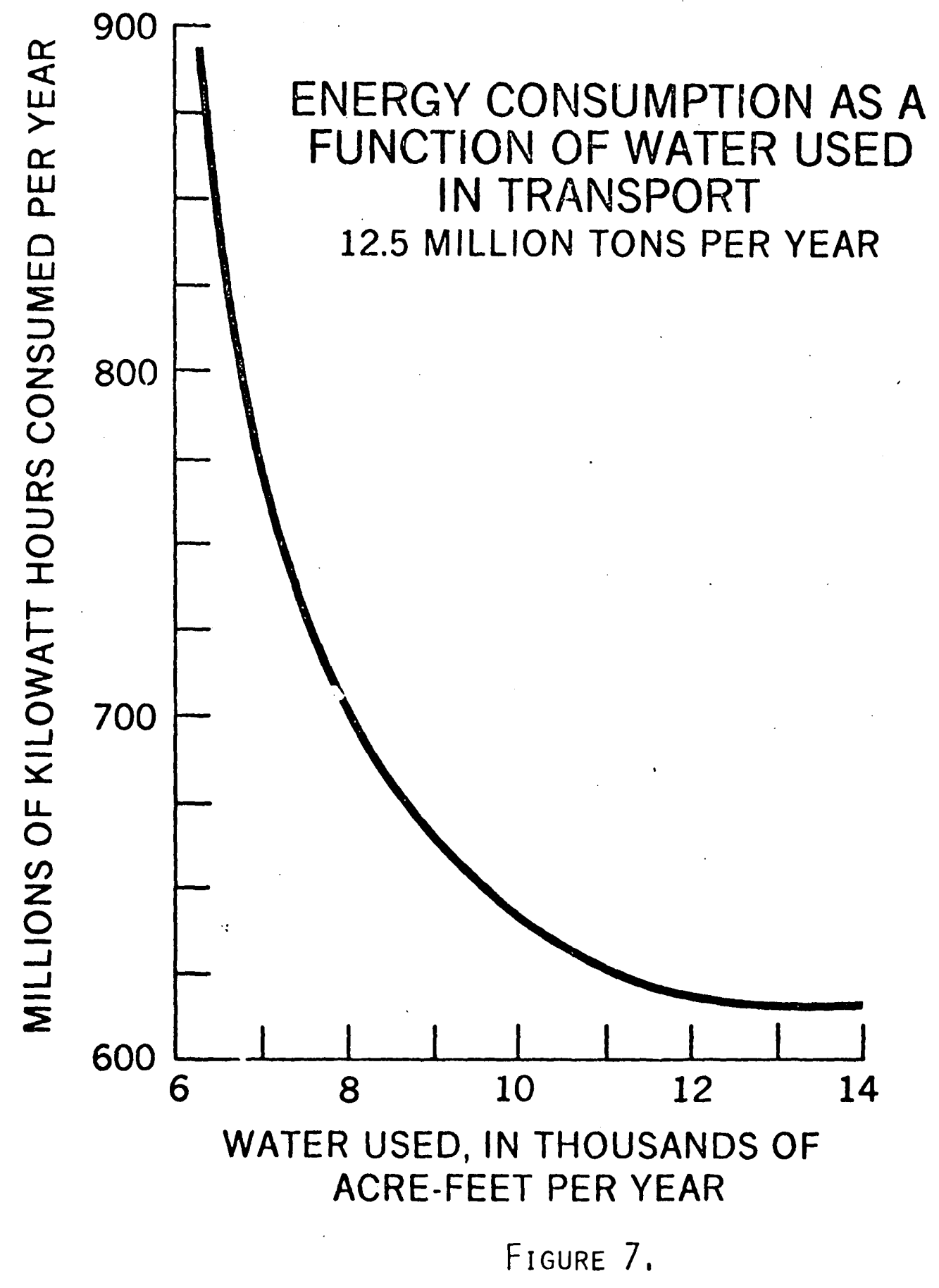




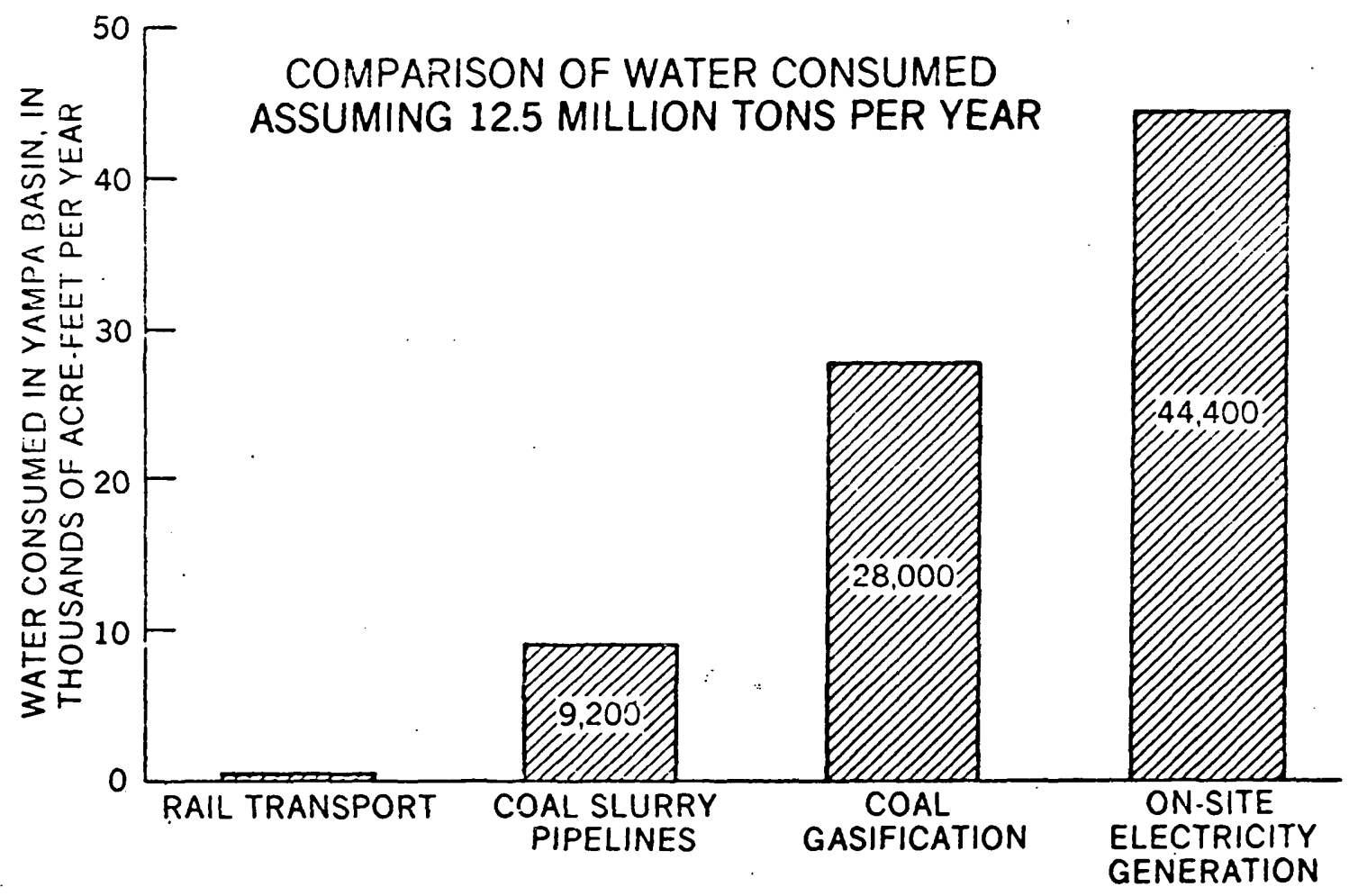

Figure 8. 


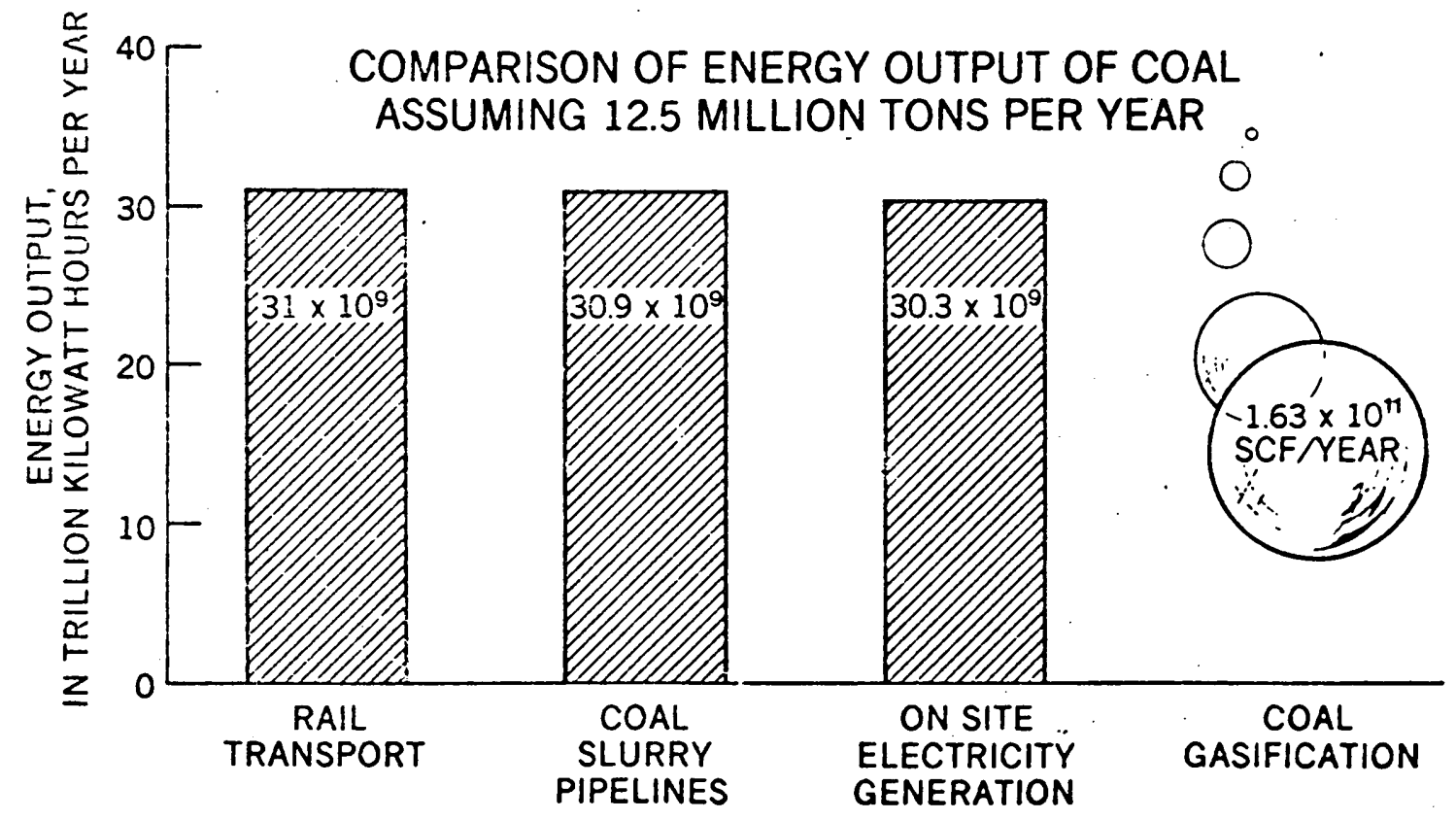

Figure 9. 


OPTIMAL QUANTITY OF WATER DEMANDED
AS A FUNCTION OF WATER COST FOR A 12.5
$\begin{array}{cc}\text { MILLION TON PER YEAR COAL SLURRY PIPELINE } \\ \text { Quantity of } \\ \text { Cost of Water } \\ \text { (\$/acre-foot) } & \begin{array}{c}\text { Water Demanded } \\ \text { (acre-feet/year) }\end{array} \\ \$ 0 & 8,500 \\ \$ 25 & 8,450 \\ \$ 50 & 8,400 \\ \$ 100 & 8,350 \\ \$ 500 & 7,875 \\ \$ 1,000 & 7,450 \\ \$ 1,500 & 7,050 \\ \$ 2,000 & 6,700 \\ \$ 2,500 & 6,500\end{array}$

TABLE 1 